\title{
Soft Skills Should be a Part of Curriculum in the Present Education System
}

\author{
Dr. I. Suresh ${ }^{1}$, Rajeswari Surisetty ${ }^{2}$, Dr. B. Ramanuja Srinivas ${ }^{3}$ \\ ${ }^{1}$ Associate Professor, ${ }^{2}$ Assistant Professor, ${ }^{3}$ Professor \\ ${ }^{1,3}$ St. Mary's Group of Institutions, Guntur, Andhra Pradesh, India \\ ${ }^{2}$ Mittapalli College Of Engineering, Tummalapalem, Guntur, Andhra Pradesh, India
}

\begin{abstract}
This research article throws light on emergence of students, employees; professionals acquiring Soft Skills Which predominantly decide the future survival in this competitive world. It acknowledges the facts that most of the majority of graduates lacked "Soft Skills "to be employed in any of the field. Due to this more than one third of the millions that graduate each year are unemployable. At this juncture, it is advised to include "Soft Skills" into a part of curriculum that should meet the requirements of present globalised world.
\end{abstract}

It leads to a failure of securing a job in any sector they opt for. It would be a great crisis of finding out future leaders of the country.

Soft skills encompass a wide terrain of personal, interpersonal attributes. It must be recognized that starting from the apparent simplest of gestures like everyday exchange of pleasantries to the complex paraphernalia of circumstances that call for effective trouble shooting or conflicts management each situation. So is the need for the right Soft Skill to fit that state. It is quite difficult to answer 'What is a Soft Keywords: Acquire, competitive, survive, globalise8kill?' because it changes in every scenario. Soft graduates, employed, requirement, adequate arSkills differ from culture to culture, place to place and knowledge

\section{INTRODUCTION}

Soft skills are determinable for success in various fields now a day, these skills emphasize on, a person's relationships with others in the work place, his character traits and interpersonal skills. Famous sociologists use this term 'Soft Skills' as a person's 'EQ' Emotional Intelligence Quotient. These are considered to be parameters to help a person to excel and climb the ladder of success faster. India is known for the second largest populated country in the world, consisting 350 millions of youth out of $28 \%$ of the country. Regrettably, $75 \%$ of young graduates and technical graduates cannot turn to be professional as they are lack of Soft Skills. Most of the students come out of schools, colleges or universities 'preloaded' with the technical skills and academic skills which cannot completely help to survive in this modern world. In India, education system is enrooted with traditional methods. Students are framed into the curriculums which enhance only their academic skills. variety of cultures exist, it is a pathetic situation that people are still in the dark regarding the boundary of Soft Skills.

We can meaningfully define that "Soft Skills are the personal attributes, personality traits, inherent social cues or communication abilities needed for success on the job, and are less quantifiable than hard skills that include specific knowledge and abilities".

Soft Skills entangle with Communication Skills, Interpersonal Skills, Motivational Skills and Analytical Skills. It is clear that Soft Skills are already existed in out day to day life which we cannot identify as a set of skills. Several reasons contribute for lacking Soft Skills among students. It has started from the Primary Education level in India which has poor quality of teaching, lack of standard curriculum maintenance, inducing of by rote methods, absence of practical application are the basic well noticed problems. 
International Journal of Trend in Scientific Research and Development (IJTSRD) ISSN: 2456-6470

Soft skills are non-academic skills associated with cognitive elements which incorporate all aspects of generic skills. Based on the vast research, the following skills are mainly identified and chosen to be imparted as a part of the curriculum from the level of Primary Education to the Graduation in all Government as well as Non-Government institutions.

\begin{tabular}{|c|c|c|c|}
\hline Attitude & Time Management & Emotional Intelligence & Result Oriented \\
\hline Communication & Motivation & Honest & Resolving Issues \\
\hline Creative Thinking & Flexibility & Logical Thinking & Self- Motivation \\
\hline Work Ethic & Problem Solving & Patience & Take Criticism \\
\hline Team Work & Critical Thinking & Public Speaking & Willingness to work \\
\hline Decision Making & Conflict Resolution & Stress Management & Work- Life Balance \\
\hline Positivity & Desire to Learn & Trouble Shooting & Writing Skills \\
\hline
\end{tabular}

The above mentioned skills are already existed with everybody, but the requirement is to horn those genuine skills in a methodical, constructive and distinct approach through Educational Institutions.

According to The Knowledge Commission of India headed by Sam Pitroda, the country needs more than 1,500 Universities to provide opportunities of higher education to eligible Indian youths. Today the country has more than 700 universities and 33,000 colleges which offer a large number of programmes in Arts, Science, Finance, Engineering, Technology, Law and Medicine. The country has grown in terms of number of colleges, universities and programmes, but seems that there is a huge gap between the quantity and quality of higher education offered in this country. It is unfortunate that a large number of institutions are being established only for yielding profits into consideration and with paying less attention towards on quality education. There are certain measures which can lead the inquisitive minds of students to possess life skills.

\section{Some meticulous approaches according to many} familiar educationists, well known psychologists and HRs of several prominent technical and nontechnical industries are:

\section{$>$ Prioritized equally to Academics in the Curriculum}

Skills should be given priority since schooling where the roots are meant to be strong enough. Or else when the students join undergraduate or graduate programmes they seem to be exhausted than excited; they exhibit confidence but can't accumulate capacity, they show familiarity but not understanding. These are occurred due to immense pressure of stuffing each detail into their minds at once. Instead of this mere confusion, Soft Skills should be placed in curriculum which can be allotted an hour in the regular academic schedule.

As we have been facing the problems that lie in every stage of our education system, neither can be blamed nor can be accountable in particular so it is the high time to mitigate this through practical application.

\section{Communicating in English is 'A must to do' task}

Communication Skills in India most specifically are nothing but conversing in English or well known word 'Spoken English'. It is absolutely beyond our imagination that how far the students who are being sent to government schools in India are able to speak at least a sentence correct though their medium of instruction is English? It is being happened because of constantly sticking to the same old methods of Translating from Mother tongue, prior for writing than speaking, restricting their minds to listen to only the teacher's monotonous teachings not letting them to have a room for thinking themselves which transforms them to an innovative thoughts.

As a consequence of this these students are unable to cop up with the present situation as well as cannot be a better competent for corporate students. Practical methods like, teaching basics of speaking a foreign language, making them understand the importance of learning it to speak alternatively, next to their mother tongue or regional language. Encourage them to speak on different topics related to their day to day life. Providing them good books as a source of learning may help to them to communicate better English.

\section{Developing Logical Thinking and Resolving issues is considerable}

Skills like Logical thinking, Resolving issues will be developed through number of tasks allotted to the 
student in different aspects from their academic subjects. A person must jump into the water to learn swimming and with constant practice; he can only do it better. Even Soft Skills training would be unsuccessful if the trainee is not convinced that it would improve him or prove beneficial for him. Correspondingly, it is the inventiveness of the teacher who is accountable for the future of the student.

\section{$>$ Inculcating Awareness of Motivation and Attitude}

Motivation, Attitude, Work-Life Balance are the skills which intertwine with our social and ethical life. These could be implanted among the students by narrating stories from our Epics, fables that impress them to learn skills in smoother way.

\section{$>$ Need Of Shaping them through Soft Skills}

In other words Soft Skills may be defined as "Shaping an individual' personality. Any educator's dream is that their students get a well rounded education and grow to become well balanced and matured personalities. So ever, this character is reflected in Soft Skills and not hard skills. People who socialize more and extrovert by nature are more appreciated than introverts who can speak less than ten sentences. Gone are the days when a person who is an expert in his field was rated as 'good' and with Soft Skills as 'nice to have'. Tables are much notably turned and it is the other way round today.

\section{Differentiating Soft Skills to Hard Skills is Essential}

On the other hand, Soft Skills must not be tackled as intrigued for the necessary hard skills required for not only to secure job but also to survive in the society in a respectful manner. The first step for the educational institutions from the initial level to the University level is to recognize the needs of the students gauge their weaknesses and then take steps to patch them up with the required training apprising their environmental, regional, cultural, psychological factors.They also need to raise the awareness of the students about the importance of differentiate Soft Skills to Hard Skills to utilize whenever they require according to the situation. It is considerably in the practical application.

\section{$>$ Awareness of Possessing SWOT analysis}

Soft Skills and doing a SWOT analysis of each and every student. Specialists can be hired for this. Students should be encouraged to read books that are focused on improving Soft Skills, attend training courses, take part in debates and socialize with their peers. Each student should be encouraged to present a topic of their choice during the seminar sessions. An addition to this, a period with a defined syllabus should be incorporated as a subject.

At school level, students may be required to do a research and present a paper or a small write-up and submit the results during a particular period. At institutes of higher learning, a Soft Skill class can be arranged with topics like leadership skill, listening or writing skills, cross cultural conflict, problem solving can be introduced. Such practices are well received by student and it basically turns out to be fun learning for them job.

\section{Recognize Soft Skills also as a Part of Academic Curriculum}

This is obvious that, Care must be taken because most colleges and universities overload students with subject's related to hard skills. It is an astonishing fact that most universities believe that the more subjects they teach, the better their students become and more are the chances of placements. Placements have become the driving force behind the choice of college / university when choosing which college they should attend after school. Universities and colleges that already have Soft Skill department have another issue. If we find the roots even in the technical based Institutions, The faculties of the technical courses have an ego the size of an elephant.

They believe that they do all the hard work in training the students to become achievers and the Communication and Soft Skills faculties takes away all the accolades after the student is placed. True interest regarding the future of the candidate in never displayed. This can be converted into a major scoring point with a little logical thinking in planning and application of courses. It clearly denotes that, technical faculty can also teach Soft Skills as they have already possess but it lies in their promoting interest towards teaching them before they jump into the lesson.

If we look deep into acquisition of these skills, they involve an individual effort to learn to be independent or self-regulated learning in adopting these skills and new knowledge. The ability to find and manage relevant information from various sources is also a criterion of this soft skill. Apart fromthis, students are 
also expected to develop an inquiry mind and crave for knowledge at whatever they are, in the sense that, they are the students of schooling, graduation or perusing university courses.. Life-long learning will enable individuals to accumulate as much knowledge and skills over the years. The ability to manage information well will allow an individual to distinguish between good and bad, right or wrong, better or the best to adopt the ultimate practices and to make sound decisions.

\section{> Implanting Soft Skills through Models / Different prescribed courses / Programmes}

As we discuss earlier, regarding the methods to develop Soft Skills among students some models are highly preferable. Each of the respective models should be useful to describe student's weaknesses and strengths. From the framework, planning, implementing and assessment, the stand alone model is definitely at an advantage. Because the course or subject is specially developed to assist students to acquire the soft skills. However, this model lacked the opportunity for students to develop and acquire soft skills as integrated with other knowledge and skills in the major discipline studies.

The existing number of credits for the respective program is also a constraint for students to sign-up for additional courses on soft skills. On the contrary, the framework, planning, implementing and assessment of the embedded model are more challenging than the stand alone model. This model requires the lecturers to master specific teaching and learning skills and then apply these skills in teaching the respective core courses for the specific program.

However, when carefully planned and used the appropriate teaching and learning strategies, this model is more effective in developing and acquiring the soft skills as integration with the other knowledge and skills in the program. In addition, this model does not require any additional courses to the already existing courses of the respective program.

Based on the weaknesses and strengths discussed, the higher education institutes are encouraged to use the embedded model as compared to the stand alone model. This is because the embedded model focus on student centered learning such experiential learning, problem-based learning and gives students the practical experience as well.

\section{Conclusion}

It is remarkable that it is necessary to include Soft Skills as a part of curriculum in order to keep body and soul together in winning the race of challenged globalization without much struggle in every sphere of this modern age. As it is the fate a fate fact that strength of a nation is, strongly dependent on the ability of its citizen to be highly intellectual, skilful and knowledgeable.

The development of human capital is thus important and necessary since it drives the nation to the envision vision and mission. Without a quality human capital, a nation will not be stronger enough. as there is no human factor that is capable to embark on new initiatives and perspectives. It is true that a quality human capital comes certainly from a quality education process.

A carefully designed and well planned education system is critical to developing such human capital, possessing dexterity and all-round development of the Nation. Thus, institutions of Primary Education to the higher learning play a very important role to produce skilled and human capital that is highly knowledgeable to meet the demand and expectations of many people. The teaching and learning processes in institutions of higher learning should be capable to provide such knowledge and skills to future graduates including it into a part of Curriculum.

\section{References:}

1. 1.Rich Dad, Poor Dad, by Robert T. Kiyoski

2. Soft Skills by John Z Sonmez

3. Working With Emotional Intelligence by Daniel Go leman

4. Effective Business Communication by Murphy; The McGraw Hill Company, $7^{\text {th }}$ Edition

5. www.softskillsindia.com

6. www.softskills.com 